PDFlib PLOP: PDF Linearization, Optimization, Protection

Page inserted by evaluation version www.pdflib.com - sales@pdflib.com 


\title{
Outcomes of Childhood Aggression in Women
}

\author{
CHERYL-LYNN PODOLSKI \\ AND L. ROWELL HUESMANN ${ }^{a}$ \\ The Institute for Social Research \\ The University of Michigan \\ P.O. Box 1248 \\ Ann Arbor, Michigan 48109-1248
}

Research has shown that early aggression predicts late aggression for both males and females. ${ }^{1}$ However, it appears that there are some sex differences in the long-term effects of childhood aggression. Whereas aggressive boys have increased rates of "externalizing" disorders as they grow up, aggressive girls have increased rates of both "externalizing" and "internalizing" disorders. ${ }^{2}$ Hence, it appears that childhood aggression in females may lead to adult depression.

The current study investigates the relationship between aggression and depression with a specific focus on sex differences in development. Whereas early aggression is expected to be positively correlated with adult aggression in both males and females, it is hypothesized that early aggression will also be positively correlated with adult depression only in females.

\section{METHOD}

The subjects consisted of 211 women and 195 men who were part of a longitudinal study of aggressive behavior. Subjects were interviewed during their first or third year of grade school (ages 6-8 or 8-10) and again during their early twenties. The procedures for the early waves of data collection are described in Huesmann and Eron. ${ }^{3}$ The follow-up interview 15 years later was conducted in person $(\mathbf{N}=$ $300)$ or by phone $(N=106)$. An "other" person who knew the subject well was also interviewed in 356 cases.

In the early waves, a peer-nominated aggression score and a measure of aggressive fantasy were obtained. ${ }^{3}$ In the late wave, measures of aggression included an aggressive personality score (MMPI F $+4+9),{ }^{4}$ self-reported indirect aggression, ${ }^{5}$ self- and other-reported mild physical aggression, ${ }^{5}$ self-reported severe physical aggression, ${ }^{3}$ and self- and other-reported criminal behavior. ${ }^{6}$ Depression was measured using the MMPI Depression Scale, ${ }^{7}$ the Beck depression inventory, ${ }^{8}$ and a global dysphoria measure. ${ }^{9}$ Normative beliefs about aggression were measured using a self-report measure about whether it was $O K$ to perform certain aggressive behaviors. ${ }^{10}$

${ }^{a}$ Tel: (313) 764-8385; fax: (313) 763-1202; e-mail: chp@umich.edu. 


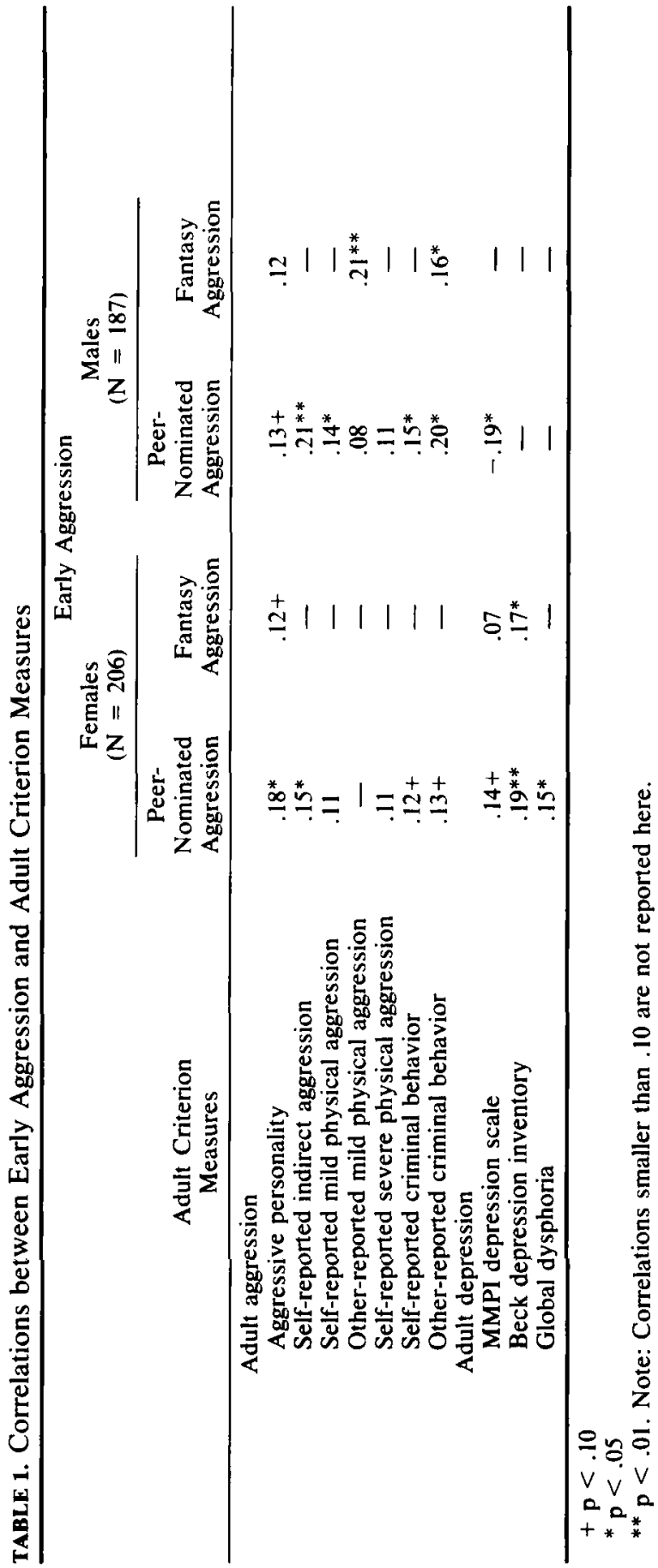


Females

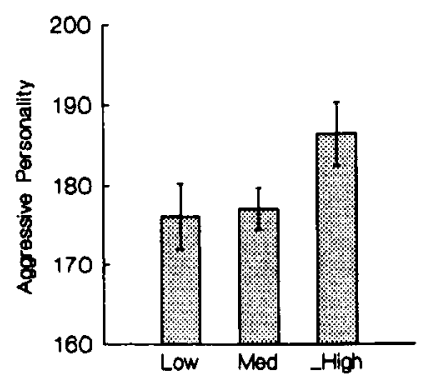

Earty Aggression Group

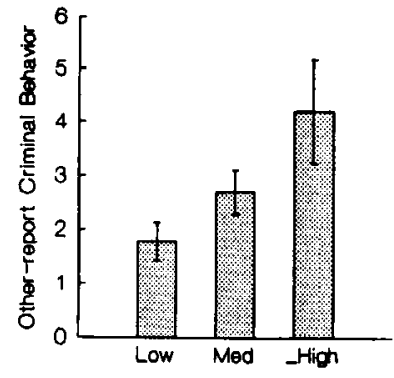

Earty Aggression Group

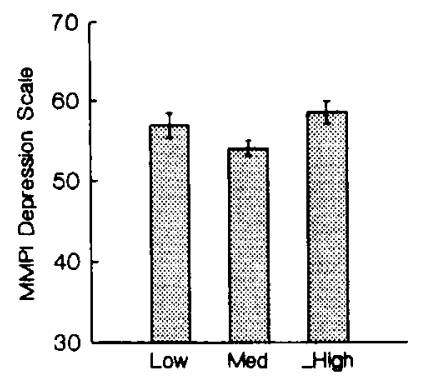

Early Aggression Group

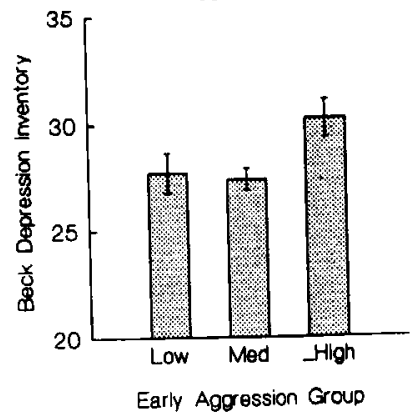

Males

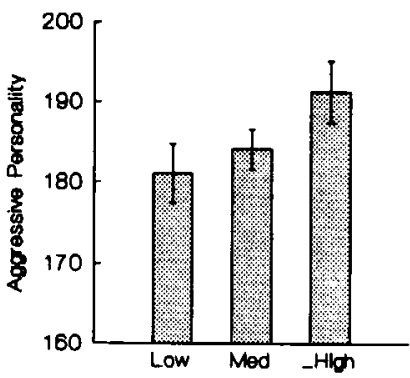

Early Agoression Group

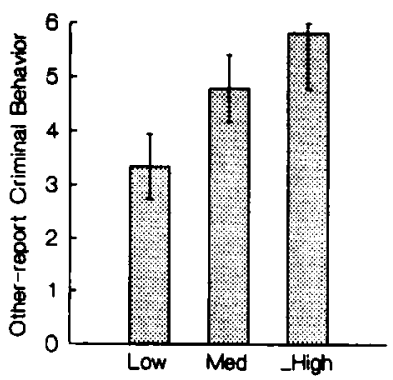

Earty Aggression Grow
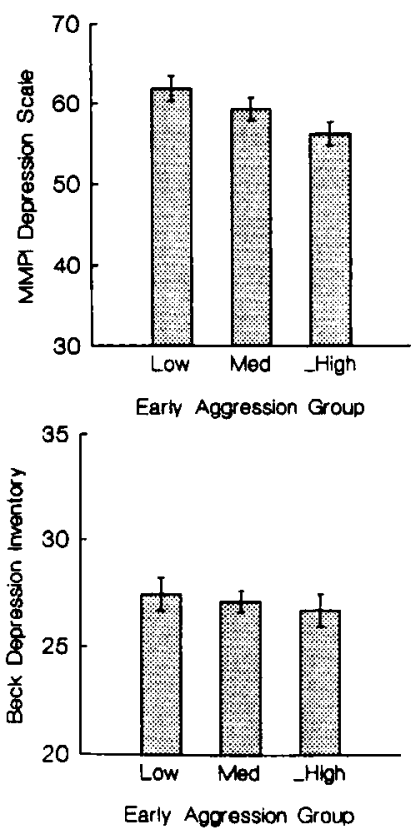

FIGURE 1. Mean adult aggression and depression scores by early aggression group for males and females. 


\section{RESULTS}

As TABLE 1 shows, for both males and females, childhood aggression is positively correlated with adult aggression. However, childhood aggression is positively correlated with adult depression in females and negatively correlated with adult depression in males. In Figure 1 these relations are illustrated with graphs that plot mean scores on adult aggression and depression for subjects who were low, medium, and high in childhood aggression. It may be that these sex differences are due to differential approval of aggression in males and females. In fact, we found that young females disapprove more of aggression than do young males $(\mathrm{t}=-4.13$, df $=366.58, \mathrm{p}<.000)$.

\section{DISCUSSION}

Early aggression was found to be positively correlated with adult depression for females but negatively for males. These findings confirm earlier studies that illustrate sex difference in the long-term effects of early aggression. Early aggressive behavior seems to lead to later externalizing and internalizing behaviors in females but only externalizing behaviors in males. These findings are consistent with Eron's" theory that differential socialization may lead to the translation of aggression into "internalizing" disorders for females. Consistent with this theory was the finding that females have stronger beliefs prohibiting the use of aggression than do males. An alternative explanation for the current findings may be that girls who learn aggressive scripts are learning behaviors that result in peer isolation. It may be that this isolation results in lack of social support that in turn leads to adult depression. Future research that investigates the accuracy of these explanations needs to be conducted.

\section{REFERENCES}

1. Huesmann, L. R., L. D. Eron, M. M. Lefkowitz \& L. O. Walder. 1984. Stability of aggression over time and generations. Dev. Psychol. 20(6): 1120-1134.

2. Robins, L. N. 1986. The consequences of conduct disorder in girls. In Development of Antisocial and Prosocial Behavior. D. Olweus, J. Black \& M. Radke-Jarrow, Eds. Academic Press. New York.

3. Huesmann, L. R. \& L. D. Eron. 1986. Television and the Aggressive Child: A CrossNational Comparison. Lawrence Erlbaum Associates. Hillsdale, NJ.

4. Huesmann, L. R., M. M. Lefkowitz \& L. D. Eron. 1978. Sum of MMPI Scales F, 4, and 9 as a measure of aggression. J. Consult. Clin. Psychol. 46: 107I-1078.

5. Bjorkqvist, K., K. OYsterman \& A. Kaukiainen. 1992. The development of direct and indirect aggressive strategies in males and females. In Of Mice and Women: Aspects of Female Aggression. K. Bjorkquist \& P. Niemela, Eds. Academic Press. New York.

6. Elliot, D. S., F. W. Dunford \& D. Huizinga. 1987. The identification and prediction of career offenders utilizing self-reporting and official data. In Prevention of Delinquent Behavior. J. D. Burchard \& S. N. Burchard, Eds.: 90-121. Sage Publications. Newbury Park.

7. Dahlstrom, W. G. \& G. S. Welsh. 1960. An MMPI Handbook. University of Minnesota Press. Minneapolis, MN.

8. Beck, A. T., C. H. Ward, M. Mendelson, J. Mock \& J. Erbaugh. 1961. An inventory for measuring depression. Arch. Gen. Psychiatry 4: 561-571. 
9. ANDrews, F. M. \& S. B. Withey. 1976. Social indicators of well-being. Plenum. New York.

10. Huesmann, L. R. \& N. G. Guerra. Children's normative beliefs about aggression and aggressive behavior. J. Pers. Soc. Psychol. In press.

11. ERON, L. D. 1992. Gender differences in violence: Biology and/or socialization? In Of Mice and Women: Aspects of Female Aggression. K. Bjorkqvist \& P. Niemela, Eds.: 89-97. Academic Press. New York. 